\title{
Pembelajaran Bahasa Indonesia dan Lingkungan
}

\author{
Novira Amir/18016203 \\ noviraamirr@gmail.com
}

Guru perlu melibatkan pendidikan lingkungan dalam pembelajaran bahasa Indonesia. Sejalan dengan Ramadhan, Sukma dan Indriyani (2019) yang menjelaskan bahwa tingkat pengetahuan dan kesadaran siswa terhadap lingkungan masih rendah sehingga guru perlu meningkatkan pengetahuan tentang lingkungan dan mitigasi bencana agar dapat merancang pembelajaran bahasa dengan pendidikan lingkungan dan mitigasi bencana. Rendahnya pengetahuan siswa terhadap lingkungan ini sangat memprihatinkan, mengingat siswa merupakan generasi penerus yang harus mampu menjaga lingkungan. Siswa perlu memiliki pengalaman dalam mengambil inisiatif yang berkaitan dengan kebutuhan mendesak di bidang tantangan global di masyarakat. Pembelajaran bahasa Indonesia yang berbasis lingkungan dapat meningkatkan kesadaran siswa terhadap setiap permasalahan yang ada di lingkungannya. Sejalan dengan angket yang disebar pada 36 mahasiswa yang berasal dari UNP, Unand, Undip, UGM, Unila, IPB, STIS, Universitas Perintis Indonesia, PNP, Universitas Syiah Kuala, Unisba, dan Binus University, pada butir 4 menyatakan setuju $(55,6 \%)$, sangat setuju $(44,4 \%)$, kurang setuju $(0 \%)$, tidak setuju $(0 \%)$ bahwa pembelajaran bahasa Indoensia berbasis lingkungan meningkatkan kesadaran siswa terhadap permasalahan lingkungan.

Pendidikan lingkungan berfokus pada masalah lingkungan dan sosial, dan dianggap fundamental jika masyarakat ingin menanamkan warganya dengan rasa tanggung jawab lingkungan, etika lingkungan, dan kesadaran ekologi sehingga pendidikan lingkungan dapat diintegrasikan pada proses pembelajaran. Pendidikan lingkungan dapat dianggap sebagai kunci karena mendorong individu untuk melindungi lingkungan dari potensi lokal dan yang ada tantangan lingkungan global. (Sukma, Ramadhan dan Indriyani, 2020). Berdasarkan angket yang disebar kepada 36 mahasiswa yang berasal dari UNP, Unand, Undip, UGM, Unila, IPB, STIS, Universitas Perintis Indonesia, PNP, Universitas Syiah Kuala, Unisba, dan Binus University, pada butir 3, menyatakan setuju (55,6\%), kurang setuju (30,6\%), sangat setuju (13,9\%), dan tidak setuju $(0 \%)$ bahwa pembelajaran bahasa Indonesia berbasis lingkungan membuat siswa tergerak untuk peduli dengan lingkungannya, sedangkan pada butir 10 , menyatakan $64,4 \%$ setuju, $27,8 \%$ sangat setuju, 2,8\% kurang setuju dan $0 \%$ tidak 
setuju bahwa pembelajaran bahasa Indonesia yang berbasis lingkungan dapat meningkatkan kepekaan terhadap nilai dan moral siswa.

Pengaplikasian pembelajaran bahasa Indonesia yang berkaitan dengan lingkungan contohnya pada keterampilan bahasa Indonesia yaitu membaca. Faktor utama yang paling menimbulkan permasalahan kemampuan membaca pemahaman adalah proses pembelajaran membaca yang belum efektif. Guru adalah komponen yang sangat menentukan dalam implementasi suatu strategi dalam mengefektifkan proses pembelajaran. (Sari, Ramadhan dan Rasyid, 2018). Guru dapat memanfaatkan membaca pemahaman tentang lingkungan sehingga siswa terfokus terhadap pembelajaran lingkungan. Dengan memfokuskan pembelajaran bahasa Indonesia pada lingkungan, maka usaha untuk menumbuhkan kesadaran siswa agar peduli pada lingkungan akan tertanam pada siswa.

Banyak sekali pembelajaran bahasa Indonesia yang dapat diambil dari lingkungan sekitar. Misalnya saja pada pemberian nama pada suatu daerah. Sejalan dengan Amin, Ramadhan, dan Ermanto (2013) Asal-usul nama daerah, hukum adat, dan macam-macam kearifan yang dicurahkan melalui berbagai mitos, dongeng, tombo, dan riwayat. Asal usul terebut dapat dijadikan pembelajaran bagi siswa, misalnya saat membahasa teks legenda, teks cerita pendek dan lain-lain. Teks tersebut dapat dikonversi kedalam berbagai genre teks lainnya seperti teks drama, puisi dan lain-lain. Menggunakan contoh yang ada pada lingkungan akan membuat siswa lebih paham dengan pembelajaran bahasa Indonesia. Berdasarkan angket yang disebar kepada 36 mahasiswa yang berasal dari UNP, Unand, Undip, UGM, Unila, IPB, STIS, Universitas Perintis Indonesia, PNP, Universitas Syiah Kuala, Unisba, dan Binus University, pada butir 6, menyatakan sangat setuju (47,2\%), setuju $(47,2 \%)$, kurang setuju $(5,6 \%)$ dan tidak setuju $(0 \%)$ bahwa lingkungan dapat menjadi sumber inspirasi siswa dalam pembelajaran bahasa Indonesia.

Contoh lainnya pengaplikasikan pembelajaran bahasa Indonesia yang berkaitan dengan lingkungan adalah teks eksplanasi, yang berisi penjelasan tentang proses yang berhubungaan dengan fenomena-fenomena alam, sosial ,ilmu pengetahuan, budaya. Teks eksplanasi berasal dari pertanyaan penulis terkait "mengapa" dan "bagaimana" suatu fenomena terjadi. Teks eksplanasi bertujuan untuk menjelaskan proses pembentukan atau kegiatan yang terkait dengan fenomena-fenomena alam, sosial, ilmu pengetahuan,atau budaya (Fitri, Ramadhan, dan Afnita, 2018). Untuk memahami dan dapat memproduksi teks eksplanasi, maka kita membutuhkan observasi terhadap lingkungan kita. Dengan melibatkan 
lingkungan, kita akan lebih paham dengan pembelajaran bahasa Indonesia. Dan bahkan juga membantu siswa untuk memahami lingkungan sekitarnya. Berdasarkan angket yang disebar kepada 36 mahasiswa yang berasal dari UNP, Unand, Undip, UGM, Unila, IPB, STIS, Universitas Perintis Indonesia, PNP, Universitas Syiah Kuala, Unisba, dan Binus University, pada butir 8 menyatakan, $75 \%$ setuju, 13,9\% sangat setuju, 11,1\% kurang setuju dan 0\% tidak setuju bahwa kemampuan observasi siswa terhadap lingkungan sangat dibutuhkan dalam pembelajaran bahasa Indonesia. Sedangkan pada butir 2, menyatakan bahwa setuju $(55,65 \%)$, sangat setuju (25\%), kurang setuju $(19,4 \%)$ dan tidak setuju (0\%) bahwa pembelajaran bahasa Indonesia membantu siswa menjadi lebih observan terhadap lingkungan.

Pemanfaatan lingkungan sebagai pembelajaran bahasa Indonesia sebenarnya tak hanya dilakukan pada saat pembelajaran di sekolah. Menurut Suardi, Ramadhan dan Asri (2019) bahwa pemerolehan bahasa pada anak dalam aspek fonologi dipengaruhi faktor lingkungan khususnya keluarga hal tersebut ditandai dengan banyaknya pembendaharaan kosakata yang mereka dapatkan di lingkungan keluarga dan sekitar. Jadi, sebenarnya bukan hal baru untuk memanfaatkan lingkungan sebagai pembelajaran bahasa Indonesia, namun pembelajaran yang berbasis lingkungan perlu dimanfaatkan secara optimal, digunakan teknik dan metode yang menarik sehingga tujuan pembelajaran tercapai.

Sikap membaca siswa akan berpengaruh pada tulisan mereka. Saat belajar membaca, dia juga mempelajari bagaimana setiap huruf dibentuk. Demikian pula dengan belajar membaca, pengalaman belajar menulis juga akan mempengaruhi minat menulis nantinya. Malas membaca mungkin disebabkan oleh proses pengenalan bacaan yang tidak menyenangkan di sekolah atau di rumah. Pemaksaan remaja terhadap seorang anak untuk membaca segera dalam waktu singkat dapat mempengaruhi minat baca mereka (Sukma, Mahjuddin, Amelia, 2017). Oleh karena itu, guru perlu membentuk lingkungan yang menyenangkan bagi siswa sehingga siswa tidak merasa terpaksa dalam melakukan pembelajaran bahasa Indonesia. Dengan melaksanankan pembelajaran bahasa Indonesia yang berbasis lingkungan, siswa dapat diajak untuk memahami linkungan sekitar sehingga pembelajaran terasa dekat dengan siswa dan siswa tidak merasa terpaksa untuk belajar bahasa Indonesia. Pembelajaran bahasa Indonesi akan menjadi suatu kegiatan yang menyenangkan karna pembelajaran yang dilakukan mengobservasi lingkungan sekitar siswa. Berdasarkan angket yang disebar kepada 36 mahasiswa yang berasal dari UNP, Unand, Undip, UGM, Unila, IPB, STIS, Universitas Perintis Indonesia, PNP, Universitas Syiah Kuala, Unisba, dan 
Binus University, pada butir 7 menyatakan, 52,8\% setuju, 41,7\% sangat setuju, 5,6\% kurang setuju dan 0\% tidak setuju bahwa dengan memahami lingkungan sekitar, siswa dapat mempelajari bahasa Indonesia lebih baik karena siswa merasa lebih "terhubung" dengan lingkungan. Siswa akan memahami lingkungannya lebih dalam dan memahami apa yang terjadi di sekitar lingkungan siswa tersebut.

Banyak sekali manfaat yang didapat dengan menerapkan pembelajaran bahasa Indonesia yang berbasis lingkungan. Seperti penelitian yang dilakukan oleh Amelia, Sukma dan Asma (2015) yang melakukan penelitian "Pembelajaraan Menulis Laporan Percobaan Dengan Pendekatan Saintifik di Sekolah Dasar" hasil dari penelitian tersebut yaitu memotivasi siswa untuk belajar menulis secara nyata karena mengumpulkan sendiri data dari objek atau fenomena percobaan yang akan ditulis laporannya, siswa merasa tertantang mengeksplorasi rasa keingintahuannya tentang fenomena alam, menyenangkan siswa karena mereka merasa bangga dapat berperan serta dalam aktivitas menulis, dan membangkitkan minat menulis siswa karena dapat mempublikasikan hasil percobaannya dalam bentuk tulisan. Berdasarkan angket yang disebar kepada 36 mahasiswa yang berasal dari UNP, Unand, Undip, UGM, Unila, IPB, STIS, Universitas Perintis Indonesia, PNP, Universitas Syiah Kuala, Unisba, dan Binus University, pada butir 1 menyatakan bahwa 66,7\% setuju, $25 \%$ sangat setuju, 8,3\% kurang setuju dan 0\% tidak setuju bahwa pembelajaran bahasa Indonesia yang berbasis lingkungan dapat membantu siswa memahami lingkungan sekitar dengan lebih baik. Pembelajaran bahasa Indonesia yang berbasis lingkungan tak hanya membuat siswa termotivasi mempelajari bahasa Indoensia, tetapi juga termotivasi untuk mempelajari lingkungannya.

Dengan dilakukannya pembelajaran bahasa Indonesia yang berbasis lingkungan, maka diharapkan juga ada peningkatan literasi dalam kehidupan masyarakat Indonesia. seperti yang dijelaskan Indriyani, Zaim, Atmazaki dan Ramadhan (2019) bahwa kegiatan literasi di sekolah menciptakan praktik literasi yang lebih inklusif, kita harus memahami hubungan praktek literasi dengan wacana, keluarga, dan lingkungan masyarakat. Maksudnya, pembelajaran bahasa Indonesia tak hanya dipengaruhi oleh lingkungan, tetapi lingkungan juga akan mempengaruhi bagaimana keadaan pembelajaran bahasa Indonesia. Jika pembelajaran bahasa Indonesia dikaitkan dengan lingkungan, maka secara tidak sadar akan tertanam pada siswa bahwa mereka mempunyai pengaruh terhadap lingkunganannya. Sejalan dengan hal tersebut, Sukma, Mahyudin, Rahmatina, dan Suriani (2019) menyatakan bahwa "The ability of teachers to teach speech skills is how teachers present speaking subjects so 
that learning is meaningful for students." Artinya kemampuan guru untuk mengajar keterampilan berbicara adalah bagaimana guru tersebut menyajikan materi sehingga pembelajaran itu bermakna bagi siswa. Bagimana guru membentuk lingkungan di dalam kelasnya akan mempengaruhi bagaimana siswa belajar. Guru memegang kendali dan mengarahkannya agar siswa dapat memanfaatkan lingkungan dengan baik sehingga tujuan pembelajaran tercapai.

Hasil pembelajaran bahasa Indonesia yang berbasis lingkungan sekitar siswa lebih memuaskan dari pada hasil pembelajaran bahasa Indonesia yang hanya mengacu kepada buku, sejalan dengan angket yang disebar pada 36 mahasiswa yang berasal dari UNP, Unand, Undip, UGM, Unila, IPB, STIS, Universitas Perintis Indonesia, PNP, Universitas Syiah Kuala, Unisba, dan Binus University, pada butir 5, bahwa 58,3\% sangat setuju, 41,7\% setuju, 0\% kurang setuju dan 0\% tidak setuju dengan pernyataan tersebut. Bahkan pada butir 9 menyatakan setuju $(61,1 \%)$, sangat setuju $(30,6 \%)$, kurang setuju $(8,3 \%)$ dan tidak setuju $(0 \%)$ bahwa pembelajaran bahasa Indonesia yang berbasis lingkungan wajib dilaksanakan semua sekolah. Melihat pentingnya dan banyak manfaat yang didapat dari pembelajaran bahasa Indonesia berbasis lingkungan, maka sangat disarankan untuk melaksanakan pembelajaran bahasa Indonesia yang berbasis lingkungan. 


\section{DAFTAR PUSTAKA}

Amelia, Rizky, Elfia Sukma, dan Nur Asma. (2015). Pembelajaraan Menulis Laporan Percobaan Dengan Pendekatan Saintifik di Sekolah Dasar. Prosiding Seminar Nasional Jurusan PGSD FIP UNP. Vol.1, No.1

Amin, Irzal, Syahrul R, dan Ermanto. (2013). CERITA RAKYAT PENAMAAN DESA DI KERINCI: Kategori dan Fungsi Sosial Teks. Jurnal Bahasa, Sastra dan Pembelajaran. Vol. 1, No. 1

Fitri, Margian Mulya, Syahrul R., Afnita. (2018). Pengaruh Model Discovery Learning Berbantuan Media Gambar Berseri Terhadap Keterampilan Menulis Teks Eksplanasi Siswa Kelas VIII SMP Negeri 25 Padang. Jurnal Pendidikan Bahasa dan Sastra Indonesia, Vol. 1 No. 7

Indriyani, Vivi, M. Zaim, Atmazaki, dan Syahrul Ramadhan. (2019). Literasi Baca Tulis Dan Inovasi Kurikulum Bahasa. KEMBARA: Jurnal Keilmuan Bahasa, Sastra, dan Pengajarannya. Vol. 5, No. 1

Ramadhan, Syahrul, Elvia Sukma dan V Indriyani. (2019). Environmental education and disaster mitigation through language learning. IOP Conf. Series: Earth and Environmental Science 314012054

Sari,Yuliana, Syahrul R, dan Yulianti Rasyid. (2018). Hubungan Antara Keterampilan Membaca Pemahaman Dengan Keterampilan Menulis Teks Laporan Hasil Observasi Siswa Kelas X SMK Negeri 3 Padang. Jurnal Pendidikan Bahasa dan Sastra Indonesia. Vol. 7, No.3

Suardi, Indah Permatasari, Syahrul R, dan Yasnur Asri. (2019). Pemerolehan Bahasa Pertama pada Anak Usia Dini. Jurnal Obsesi : Jurnal Pendidikan Anak Usia Dini. Vol. 3, No. 1

Sukma, Elfia, R. Mahyudin, Rahmatina, dan A.Surian. (2019). Problems In Oral Language Teaching In Primary School. Advances in Social Science, Education and Humanities Research. Vol. 301

Sukma, Elfia, Ritawati Mahjuddin, dan Rizky Amelia. (2017). Literacy Media Development in Improving Reading and Writing Skill of Early Class Students in Elementary School Padang Utara Padang. Advances in Social Science, Education and Humanities Research. Vol. 118

Sukma, Elfia, S. Ramadhan dan V Indriyani. (2020). Integration of environmental education in elementary schools. Journal of Physics: Conference Series 1481 


\section{LAMPIRAN}

Tabel 1

Angket Kaitan Pembelajaran Bahasa Indonesia dengan Lingkungan

\begin{tabular}{|c|c|c|c|c|c|}
\hline No. & Pertanyaan & SS & $\mathbf{S}$ & KS & TS \\
\hline 1. & $\begin{array}{l}\text { Pembelajaran bahasa Indonesia dapat membantu siswa } \\
\text { memahami lingkungan sekitar dengan lebih baik }\end{array}$ & $25 \%$ & $66,7 \%$ & $8,3 \%$ & - \\
\hline 2. & $\begin{array}{l}\text { Pembelajaran bahasa Indonesia membantu siswa } \\
\text { menjadi lebih observan terhadap lingkungan }\end{array}$ & $25 \%$ & $55,6 \%$ & $19,4 \%$ & - \\
\hline 3. & $\begin{array}{l}\text { Pembelajaran bahasa Indonesia dapat membuat siswa } \\
\text { tergerak untuk peduli dengan lingkungannya }\end{array}$ & $13,9 \%$ & $55,6 \%$ & $30,6 \%$ & - \\
\hline 4. & $\begin{array}{l}\text { Pembelajaran bahasa Indonesia yang berbasis } \\
\text { lingkungan dapat meningkatkan kesadaran siswa } \\
\text { terhadap setiap permasalahan yang ada di } \\
\text { lingkungannya }\end{array}$ & $44,4 \%$ & $55,6 \%$ & - & - \\
\hline 5. & $\begin{array}{l}\text { Hasil pembelajaran bahasa Indonesia yang berbasis } \\
\text { lingkungan sekitar siswa lebih memuaskan dari pada } \\
\text { hasil pembelajaran bahasa Indonesia yang hanya } \\
\text { mengacu kepada buku }\end{array}$ & $58,3 \%$ & $41,7 \%$ & - & - \\
\hline 6. & $\begin{array}{l}\text { Lingkungan dapat menjadi sumber inspirasi siswa } \\
\text { dalam pembelajaran bahasa Indonesia }\end{array}$ & $47,2 \%$ & $47,2 \%$ & $5,6 \%$ & - \\
\hline 7. & $\begin{array}{l}\text { Dengan memahami lingkungan sekitar, siswa dapat } \\
\text { mempelajari bahasa Indonesia lebih baik karena siswa } \\
\text { merasa lebih "terhubung" dengan lingkungan }\end{array}$ & $41,7 \%$ & $52,8 \%$ & $5,6 \%$ & - \\
\hline 8. & $\begin{array}{l}\text { Kemampuan observasi siswa terhadap lingkungan } \\
\text { sangat dibutuhkan dalam pembelajaran bahasa } \\
\text { Indonesia }\end{array}$ & $13,9 \%$ & $75 \%$ & $11,1 \%$ & - \\
\hline 9. & $\begin{array}{l}\text { Pembelajaran bahasa Indonesia yang berbasis } \\
\text { lingkungan wajib dilaksanakan semua sekolah }\end{array}$ & $30,6 \%$ & $61,1 \%$ & $8,3 \%$ & - \\
\hline 10. & $\begin{array}{l}\text { Pembelajaran bahasa Indonesia yang berbasis } \\
\text { lingkungan dapat meningkatkan kepekaan terhadap } \\
\text { nilai dan moral siswa }\end{array}$ & $27,8 \%$ & $64,4 \%$ & $2,8 \%$ & - \\
\hline
\end{tabular}

Jumlah responden adalah 36 mahasiswa yang berasal dari UNP, Unand, Undip, UGM, Unila, IPB, STIS, Universitas Perintis Indonesia, PNP, Universitas Syiah Kuala, Unisba, dan Binus University.

\section{Keterangan:}

SS : Sangat Setuju

S : Setuju

KS : Kurang Setuju

TS : Tidak Setuju 